\title{
A integração entre as atividades de leitura, oralidade, escrita e reflexão linguística: uma proposta para o ensino de Língua Portuguesa no Ensino Médio
}

DOI: http://dx.doi.org/10.21165/el.v48i3.2210

Heliud Luis Maia Moura'

\section{Resumo}

O objetivo deste artigo é estudar a integração entre as atividades de leitura, oralidade, escrita e reflexão linguística no Ensino Médio, considerando-as como necessárias à ampliação da capacidade linguístico-discursiva e sociorretórica dos aprendizes, compreendendo o trânsito dos sujeitos-cidadãos pelos diferentes espaços socioinstitucionais de produção de linguagem, os quais exigem dos indivíduos multiproficiências em contextos sociopragmáticos variados e específicos. Tomo como referencial as postulações de Marcuschi $(2005,2008)$, Koch $(2003,2004,2006,2008)$, Koch e Elias (2009a), Bazerman (2011), Bakhtin (2006, 2010a, 2010b, 2011, 2016, 2017b), Habermas (2012), Moura (2016, 2017) e Schneuwly e Dolz (2010). Para os autores, sob diferentes perspectivas epistemológicas, as atividades de ensino de língua são constituídas na dinâmica das práticas sociais (gêneros). O corpus em estudo consta de uma análise das atividades desenvolvidas por uma professora do Ensino Médio em sala de aula; estas estão organizadas em 04 (quatro) momentos sobre os quais procedo análises reflexivas, levando-me a concluir acerca da necessidade de integração entre as diferentes ações didáticas realizadas tanto em sala de aula quanto no espaço escolar como um todo, o que vem a contribuir para a autonomia dos sujeitos nos diferentes espaços sociointerativos.

Palavras-chave: língua portuguesa; ensino; atividades didáticas integradas; gêneros discursivos.

1 Universidade Federal do Oeste do Pará (UFOPA), Santarém, Pará, Brasil; heliudlmm@yahoo.com.br; https://orcid.org/0000-0003-3259-6614 


\title{
The integration among the activities of reading, orality, writing and linguistic reflection: a proposal for the teaching of Portuguese Language in High School
}

\begin{abstract}
The aim of this article is to study the integration among reading, speaking, writing and linguistic reflection activities in high school, considering them as necessary for the expansion of the learners' discursive and socio-rhetorical capacity, understanding the transit of the citizen-subjects through the different socio-institutional spaces for language production, which require multiproficient individuals in varied and specific sociopragmatic contexts. I take as reference the postulations of Marcuschi $(2005,2008)$, Koch $(2003$, 2004, 2006, 2008), Koch and Elias (2009a, 2009b), Bazerman (2011), Bakhtin (2006, 2010a, 2010b, 2011, 2016, 2017b), Habermas (2012), Moura $(2016,2017)$ and Schneuwly and Dolz (2010). For the authors, under different epistemological perspectives, language teaching activities are constituted in the dynamics of social practices (genres). The corpus under study consists of an analysis of the activities developed by a high school teacher in the classroom; These are organized in four (4) moments about which I carry out reflective analyzes, leading me to conclude about the need for integration among the different didactic actions performed both in the classroom and in the school space as a whole, which contributes for the autonomy of the subjects in different socio-interactive spaces.
\end{abstract}

Keyword: Portuguese language; teaching; integrated learning activities; discursive genres.

\section{Introdução}

Este trabalho tem como objetivo estudar a integração entre as atividades de leitura, oralidade, escrita e reflexão linguística no Ensino Médio, considerando que essa integração faz-se necessária à ampliação da capacidade linguístico-discursiva e retórica dos alunos, já que, no trânsito pelos espaços socioinstitucionais de produção de linguagem, são exigidas, desses indivíduos, multiproficiências linguístico-discursivas, coadunadas com diferentes contextos sociopragmáticos de produção de sentido. A teoria que embasa este trabalho está ancorada nas postulações de Marcuschi $(2005,2008)$, Koch $(2003,2004$, 2006, 2008), Koch e Elias (2009a, Bazerman (2011), Bakhtin (2006, 2010a, 2010b, 2011, 2016, 2017), Habermas (2012), Moura (2016, 2017) e Schneuwly e Dolz (2010). O corpus, em estudo, consta de análises de atividades didáticas realizadas por uma professora do Ensino Médio, cujo foco constitui-se da integração entre as mencionadas atividades, divididas em quatro momentos, a partir dos quais faço considerações analítico-reflexivas. A análise dos dados leva-me a concluir acerca da necessidade da integração entre as ações didáticas, cujo centro são os gêneros discursivos e o dialogismo existente entre estes na vida social. 


\section{Bases teóricas}

\subsection{Noções preliminares}

Segundo Marcuschi $(2005,2008)$, as atividades de oralidade reafirmam as práticas culturais mobilizadas em diferentes contextos interativos, constituindo os indivíduos em sujeitos de linguagem. Segundo Koch e Elias (2009a), a leitura implica a (re)construção de sentidos em veiculação nos diferentes textos, nos quais atuam estratégias sociocognitivas e metacognitivas, ativando-se conhecimentos prévios de ordem linguística, pragmática e interacional, pela ocasião da interação com o texto. Para Bazerman (2011), a escrita deve ser constituída em agência. Com ela, o sujeito imprime valores, juízos, originalidade e individualidade, atuando como sujeito dos seus dizeres e construindo-se como tal nos contextos pragmáticos nos quais se acha imerso. Para propósitos didáticos, os conceitos referentes à oralidade, leitura e escrita são colocados numa espécie de sequência. No entanto, é valido afirmar que a oralidade não subsiste, do ponto de vista da construção de sujeitos responsivos, sem a conexão necessária com a leitura e vice-versa e que estas constituem-se como essenciais para a constituição de sujeitos escritores capazes de se posicionar diante do que dizem nos vários contextos sociopragmáticos em que estão imersos, imprimindo avaliações críticas aos seus discursos, no âmbito da produção de diferentes gêneros escritos. Por conseguinte, as atividades, acima colocadas, exigem dos indivíduos a reflexão linguística, na medida em que agem metadiscursivamente e metarreflexivamente sobre os sentidos produzidos nas várias atividades sociais.

Para Koch (2003, 2004, 2006, 2008), a língua é um espaço de interação, por meio do qual os sujeitos constroem e são construídos em sentidos, sendo estes múltiplos, diferenciados e específicos em seus diversos contextos de realização. Segundo as postulações de Bakhtin, há um dialogismo constitutivo entre os diferentes enunciados existentes na prática social, de modo que as atividades linguísticas de leitura, oralidade, escrita e reflexão linguística são também constituídas nesse dialogismo. Nesse sentido, ler, falar, escrever e agir reflexivamente acerca dos sentidos que (re)construímos apresentamse sempre como ações intercambiáveis, mútuas ou recíprocas, já que as atividades linguageiras socialmente instituídas também não são exclusivas e isomórficas, mas dinâmicas quando do nosso trânsito pelos espaços de produção do significado. Assim, sendo a língua uma instância de interação, quando, por exemplo, falamos, nossas falas são tributárias do que lemos e ouvimos, o que, inevitavelmente, descamba nas diferentes produções escritas, as quais consorciam-se com a natureza específica dos sentidos a serem produzidos nos vários contextos sociopragmáticos.

Considerando as postulações de Moura (2016, 2017), a reflexão linguística constitui um ato semântico-discursivo em que o indivíduo age reflexivamente acerca do seu discurso, observando-se um jogo de significações advindo da sua capacidade de repensar o que disse. Neste trabalho, analiso o trânsito entre as mencionadas atividades, já que uma atividade convoca a outra. Assim, é na leitura de textos que os sujeitos (re)constroem 
sentidos e tomam posição sobre estes nas atividades de oralidade. Pela ação, na escrita, refletem sobre o que discursivizam, levando em conta as consequências de sua enunciação. Logo, há uma interseção necessária na mobilização dessas atividades. 0 corpus, em estudo, constitui-se de propostas de atividades para alunos do Ensino Médio, utilizando-se textos dos gêneros fôlder, propaganda, cartaz, ofício, panfleto, discussão oral e debate. As análises realizadas, a priori, levam-me a concluir acerca da necessidade de integração entre estas atividades, já que essa interrelação leva a uma significativa transformação na capacidade dos alunos de argumentar sobre os mais diferentes discursos.

\subsection{Oralidade, leitura, escrita e reflexão linguística: conceitos e desdobramentos}

De acordo com os PCNs, as atividades de oralidade, leitura, escrita e reflexão linguística são recursos didático-pedagógicos que possibilitam ao professor a inserção dos alunos nos espaços socioinstitucionais de produção de linguagem, entendendo-se que tais espaços são múltiplos, heterogêneos e diferenciados, o que exige dos indivíduos multiproficiências discursivas e sociorretóricas, consoantes com as características interacionais e sociopragmáticas desses contextos. Para Marcuschi (2005, p. 25), as atividades de oralidade são relevantes porque devem voltar-se para a preservação das práticas culturais mobilizadas nos contextos sócio-históricos específicos dos indivíduos que integram o espaço escolar. Nesse sentido, afırma que

[...] o trabalho com a oralidade pode, ainda, ressaltar a contribuição da fala na formação cultural e na preservação de tradições não escritas que persistem mesmo em culturas em que a escrita já entrou de forma decisiva. Veja-se o caso tão ilustrativo dos contos populares ainda tão vivos em nosso povo não só no interior, mas também nas áreas urbanas. Dedicar-se ao estudo da fala é também uma oportunidade singular para esclarecer aspectos relativos ao preconceito e à discriminação linguística, bem como suas formas de disseminação. Além disso, é uma atividade relevante para analisar em que sentido língua é um mecanismo de controle social e reprodução de esquemas de dominação e poder implícitos em usos linguísticos na vida diária, tendo em vista suas íntimas, complexas e comprovadas relações com as estruturas sociais.

Enquanto prática cultural, a oralidade é uma forma de manifestação dos indivíduos, para a qual concorrem todo um conjunto de experiências e maneiras de ver a realidade dos segmentos e grupos a que pertencem tais indivíduos. Postulo, por outro âmbito, que a prática da oralidade não é somente um meio pelo qual os indivíduos dizem alguma coisa, mas um instrumento sociopolítico de construção das identidades integrantes do espaço escolar, que se expressam segundo os códigos sociais e culturais dos grupos a que pertencem. 
No que concerne à leitura, Koch e Elias (2009, p. 11) afırmam:

- a leitura é uma atividade na qual se leva em conta as experiências e os conhecimentos do leitor;

- a leitura de um texto exige do leitor bem mais que o conhecimento do código linguístico, uma vez que o texto não é simples produto da codificação de um emissor a ser decodificado por um receptor passivo.

Com base em Koch e Elias (2009), é válido afırmar que a leitura é um processo contínuo de (re)construção de sentidos veiculados num dado texto, em que agem diferenciadas estratégias sociocognitivas e metacognitivas, consorciadas com os conhecimentos prévios ativados pelo leitor pela ocasião da interação com esse texto.

Para Bazerman (2011), a escrita nos concede uma semiprivacidade para enfrentar nossas ideias, memórias, emoções, como também nossos desejos para construção de uma presença no mundo. Concede-nos, além disso, instrumentos para a nossa intervenção nesse mundo, em que tomamos posições sobre diferentes ações de linguagem em mobilização em práticas sociais diversas, para as quais temos um propósito.

Considerando a natureza dialógica das preposições de Bakhtin e tendo em conta o encontro destas com a ideia de que as atividades de leitura, oralidade, escrita e reflexão linguística se constituem nessa dialogicidade e integração, veja-se o que postula Bakhtin (2010a, p. 348) nesse sentido:

Natureza dialógica da consciência, natureza dialógica da própria vida humana. A única forma adequada de expressão verbal da autêntica vida do homem é o diálogo inconcluso. A vida é dialógica por natureza. Viver significa participar do diálogo: interrogar, ouvir responder, concordar, etc.. Nesse diálogo o homem participa inteiro e com toda vida: com os olhos, os lábios, as mãos, a alma, o espírito, todo o corpo, os atos. Aplica-se totalmente na palavra, e essa palavra entra no tecido dialógico da vida humana, no simpósio universal.

Com base em Bakhtin, postulo que os atos de linguagem, em todas as suas dimensões, constituem-se na reciprocidade dialógica, intercambiável, em que um ato penetra no outro inelutavelmente, pois a nossa vida implica essa dinâmica: lemos, dizemos do que lemos num efeito de responsividade engajada e, por conseguinte, escrevemos, tomando posição avaliativa no âmbito dessa escrita. Consequentemente, refletimos criticamente sobre tudo isso, já que o mundo social não chega para nós reificado, o que demanda uma intervenção constante nele, atos estes que deveriam ser reconstituídos na escola, de forma a construir cidadãos reflexivos/responsivos. 
Postulo, a partir da teoria do agir comunicativo propugnada por Habermas (2012), que só é possível compreender as ações de linguagem como atravessadas por pretensões de validade nas relações intersubjetivas, o que também conduz ao próprio modo como os indivíduos agem reciprocamente em determinadas condições de produção de seus discursos, observando-se, aí, regulações de várias ordens ou naturezas, com diferenciações de sentido, afetadas por essas mesmas regulações.

\subsection{Atividades didáticas integradas no Ensino Médio: uma proposta}

No contexto do Ensino Médio, as atividades didáticas integradas devem estar consorciadas com os conhecimentos e habilidades a serem dominados pelos estudantes no âmbito dos diferentes gêneros. No entanto, deve haver a prioridade para os gêneros da ordem do argumentar. O domínio desses gêneros deve ampliar a capacidade linguístico-discursiva dos sujeitos, especificamente quando se trata da capacidade de argumentar, contraargumentar, avaliar, analisar, criticar e intervir em diferentes contextos sociopragmáticos, o que pode dar-se: (i) por meio de atividades de leitura, nesse sentido, a ação leitora se constitui como predominantemente analítica e reflexiva; (ii) por meio de atividades de oralidade, nas quais os sujeitos consigam posicionar-se acerca do que dizem, avaliando seus próprios dizeres, numa perspectiva metadiscursiva/metarreflexiva; (iii) por meio de atividades de produção escrita, mesmo que ainda escrevam minimamente sobre determinados temas; (iv) por meio de atividades de reflexão linguística, que perpassam as atividades anteriormente citadas.

Segundo as noções discutidas anteriormente, propõe-se uma intervenção constante dos leitores/falantes/escritores nos diferentes gêneros de textos, o que lhes possibilita um aprofundamento paulatino acerca das questões veiculadas nesses textos, de forma a estabelecerem cotejos sobre diferentes abordagens de um mesmo tema. Assim, cabe ao professor conduzir as atividades: apontando questões; estabelecendo analogias; propondo inferências diversas sobre os sentidos em veiculação não só nos textos escritos, como também nos textos orais. Essa atitude de ensinar pressupõe um educador também leitor, capaz de realizar espécies de descobertas, conjuntamente com seus alunos, sobre os significados carreados nessas produções. Isto constitui um procedimento constante de análise dos vários textos, uma espécie de maiêutica socrática, por meio da qual os indivíduos conseguem, pouco a pouco, desvelar os sentidos produzidos pelos textos, na sua necessária conexão com o interdiscurso, com os diferentes contextos em que tais textos são produzidos e em que há uma posição sujeito em mobilização numa dada ação discursiva.

No âmbito dos gêneros da ordem do argumentar, dentre eles, os gêneros do domínio jornalístico, o professor poderá escolher os seguintes: reportagens, editoriais, entrevistas, crônicas políticas, cartas do leitor, cartas ao leitor, charges, tiras, cartuns, propagandas, notícias, artigos de opinião, matérias assinadas, publicidades de diferentes áreas. 
As ações didáticas do professor poderão iniciar com uma das atividades didáticas em questão, não havendo a realização de atividades sequenciais do tipo sequência didática, postulada por Schneuwly e Dolz (2010). Assim, o professor poderá começar pela oralidade, a partir de gêneros orais já dominados pelos alunos e sobre temas que eles já conhecem. Após isso, poderá trabalhar as atividades de leitura, considerando os temas tratados nos gêneros orais, o que, de certa forma, facilita o entendimento de alguns assuntos. Desse modo, a leitura deverá se dar sobre temáticas já abordadas em gêneros orais como: pequenas exposições; minisseminários; rodas de conversa; debates abertos; relatos de experiência. O professor poderá trazer textos que abordem outros posicionamentos sobre temas minimamente tratados (ou não) nesses gêneros, mas que, agora, devem ser aprofundados com a leitura de textos de gêneros escritos, como reportagens, editoriais, artigos de divulgação científica, artigos científicos, entrevistas, ensaios filosóficos, poemas, contos e crônicas literárias. A apropriação, por parte dos alunos, de diferentes versões acerca dos temas oralizados, contribuirão, certamente, para a ampliação/dinamização da capacidade discursiva dos sujeitos do espaço escolar, especificamente no âmbito da própria sala de aula e/ou da escola como um todo.

Considerando as atividades de leitura realizadas dentro e fora da sala de aula ${ }_{2}$ o professor poderá implementar um novo debate/discussão sobre as temáticas veiculadas nesses textos, o que significa dizer que, agora, terão agregado novos conhecimentos acerca das questões já debatidas no momento anterior. Feitos novos debates, o docente deverá propor, ainda que inicialmente, uma atividade escrita, desde que esta se realize em gêneros que os estudantes já dominem e usando temas com os quais têm mais facilidade de escrever. Mas as atividades de leitura propostas, antes, poderão estender significativamente a capacidade desses sujeitos de discursivizarem, sobretudo de avaliarem as posições SUJEITO mobilizadas nos textos lidos. Logo, sua escrita deve ser muito mais agentiva (cf. BAZERMAN, 2011), isto na medida em que se posicionam sobre os sentidos que thes chegam, avaliando-os, analisando-os reflexivamente, construindo posições acerca do que os autores desses textos propõem.

Tendo produzido suas versões acerca das temáticas em circulação nos textos lidos, poderão, com a condução do professor, avaliar, discutir, construir "respostas" reflexivas sobre os seus próprios dizeres (cf. BAKHTIN, 2006, 2010a, 2010b, 2016a, 2016b, 2017), é o que podemos chamar, de acordo com os PCNs, de reflexão linguística. Mas, nesse momento, a intervenção do professor é fundamental, já que deverá propor questionamentos sobre as posições veiculadas pelos alunos quando da sua atividade de escrever sobre determinados assuntos. Desse modo, a sua escrita não é final ou definitiva, pois poderão informar-se mais sobre as temáticas lidas, assim como deverão pensar sobre o modo como discursivizaram, podendo intervir nos seus próprios textos, agregando informações mais profundas sobre o que construíram, não só nos textos escritos como também nos textos orais que produziram. 


\section{Analisando uma ação pedagógica tendo como instrumento as ADIs}

\subsection{Contextualizando a pesquisa}

Considerando o que propõe as ADIs, analiso, nesta seção, as ações pedagógicas realizadas por uma professora ${ }^{2}$ numa turma de $1^{\circ}$ ano do Ensino Médio. Primeiramente, a docente apresenta, de modo sucinto, o seu projeto, tendo como espaço didáticopedagógico as ADIs. Observemos, então, o que diz Coelho $(2018$, p. 36) a esse respeito:

O projeto de intervenção no âmbito das Atividades Didáticas Integradas-ADIs.

Diferentemente de outras propostas para o ensino de língua portuguesa que, geralmente, primam em focalizar prioritariamente em uma determinada atividade, na maioria das vezes, na escrita, este trabalho visa, ao contrário, integrar leitura, oralidade, escrita e reflexão linguística, conforme sugerem os Parâmetros Curriculares Nacionais (PCNs). Propor ações pedagógicas para que essas atividades sejam desenvolvidas concomitantemente, isto é, sem privilegiar nenhuma delas. Para tanto, elaborou-se um Projeto Didático (PD) composto por ADIs. A opção por essas duas propostas didáticas justificase, primeiramente, porque a concepção adotada neste trabalho pauta-se na perspectiva interacionista, que concebe a linguagem como forma de interação entre interlocutores em diferentes contextos sociais. Porque, conforme Bakthin, a língua se materializa por meio de enunciados e não somente por formas fixas e acabadas. Isto é, adotamos uma concepção de linguagem em que os sujeitos interagem no meio social para fins reais de comunicação, seja para opinarem, para persuadirem, para não serem enganados, para infinitos propósitos.

As ações planejadas, portanto, nesta pesquisa têm o intento de oportunizar aos educandos a ampliação de seus conhecimentos em relação à língua que falam para, assim, aprofundarem suas capacidades linguísticas, textuais, discursivas a fim de atuarem com autonomia e criticidade frente às diversas situações em que participam, sejam por meio do texto verbal, não-verbal ou oral, tanto no espaço escolar, quanto fora dos muros da escola.

De acordo com a professora, as ADIs constituem ações pedagógicas planejadas com o objetivo de inserir os estudantes em diferentes contextos sociais de linguagem, compreendendo que essas atividades não são estanques e levam os indivíduos a ampliarem sua capacidade textual-discursiva, proporcionando-Ihes autonomia e criticidade.

2 Os dados analisados, neste trabalho, constam da dissertação de mestrado de Rosiane Maria da Silva Coelho, defendida, em dezembro de 2018, no Mestrado Profissional em Letras - PROFLETRAS - da Universidade Federal do Oeste do Pará, sob orientação do Prof. Dr. Heliud Luis Maia Moura. 


\subsection{As ADls e o trabalho com os gêneros textuais}

Para a docente, o trabalho, na perspectiva das ADIs, implica uma ação pedagógica na qual os gêneros textuais/discursivos constituem um espaço necessário ao desenvolvimento da capacidade interativa dos sujeitos. Vejamos o que nos diz Coelho (2018, p. 37):

A linguagem compreendida como interação entre sujeitos não pode vincular-se a um ensino a partir de formas estanques, desvinculadas de seus contextos de uso. Dessa maneira, as postulações de Bakthin são pertinentes.

O emprego da língua efetua-se em forma de enunciados (orais e escritos) concretos e únicos proferidos pelos integrantes desse ou daquele campo da atividade humana. Esses enunciados refletem as condições específicas e as finalidades de cada referido campo não só por seu conteúdo temático e pelo estilo da linguagem, ou seja, pela seleção dos recursos lexicais, fraseológicos e gramaticais da língua mas, acima de tudo, por sua construção composicional. Todos esses três elementos - o conceito temático, o estilo, a construção composicional - estão indissoluvelmente ligados no todo do enunciado e são igualmente determinados pela especificidade de um determinado campo da comunicação. Evidentemente, cada enunciado particular é individual, mas cada campo de utilização da língua elabora seus tipos relativamente estáveis de enunciados, os quais denominamos gêneros do discurso. (BAKTHIN, 2011, p. 268).

Reportando-se às concepções de Bakthin, acima citadas, Coelho (2018, p. 37) afirma que

[...] em todos os espaços sociais onde interagimos produzimos diferentes gêneros textuais que respondem a diversas e diferentes necessidades de comunicação entre os interlocutores. Bate-papo, avisos, propagandas, placas de trânsito, símbolos, etc., a multiplicidade de gêneros é variada, porque cada situação precisa de uma maneira única para se estabelecer.

Ensinar com a utilização dos gêneros é uma alternativa para fugir do prescritivismo, da anulação das vozes dos sujeitos, da imposição de um modelo de língua irreal, abstrato, em que a língua fica à disposição do falante.

A docente, em seu discurso, dá ênfase ao trabalho com os gêneros, considerando-os como necessários a uma intervenção pedagógica à altura das exigências dos espaços sociais e institucionais por onde transitam os sujeitos que, nesse caso, devem se constituir como agentes das/nas mais diversas atividades de linguagem, tanto no âmbito do escrito quanto do oral, sendo capazes de intervir nesses espaços de forma proficiente, engajada e avaliativa. 


\subsection{Descrição e realização de uma ação pedagógica na perspectiva das ADIs}

Nesta subseção, coloco dados relativos ao contexto da ação pedagógica realizada pela professora, assim como dos momentos em que se deu a mencionada ação. Focando primeiramente, aqui, no que Coelho (2018, p. 37-38) chama de primeiro momento:

Nesta seção descrevemos a intervenção pedagógica realizada por meio de um projeto com as ADIs (Atividades Didáticas Integradas) entre leitura, oralidade, escrita e reflexão linguística.

As atividades do projeto didático aconteceram nos meses de fevereiro e março de 2018, precisamente de 05 de fevereiro a 28 de março, numa escola da zona urbana da cidade de Santarém - PA, o público participante foram os estudantes do Projeto Mundiar do Ensino Médio.

É importante destacar que o tema do projeto desenvolvido surgiu a partir de uma problemática recorrente na turma, isto é, os meninos apresentavam um comportamento agressivo em relação às meninas, isto é, não as respeitavam e a comunicação era bastante violenta, ou seja, os estudantes utilizavam palavras obscenas e ofensivas na interação com as meninas.

\section{$1^{\circ}$ Momento: Discutir é preciso?!}

A atividade inicial aconteceu numa roda de conversa e deveria partir da leitura de cartazes de uma campanha sobre o assédio sexual contra mulheres, no carnaval, postados no Facebook. Porém, antes de iniciar a discussão sobre o tema, fiz o levantamento dos conhecimentos prévios sobre o assunto em pauta. Questionei se sabiam o que era assédio. A maioria dos alunos não sabia, apesar de alguns já terem ouvido falar sobre esse assunto, contudo uma aluna disse que era um tipo de violência sexual. Após a fala dessa aluna, outros estudantes participaram citando, principalmente, o estupro como exemplo de violência sexual. Foi, então que, antes de apresentar os cartazes, realizei a leitura do fôlder "Chega de fiu fiu" - Vamos falar sobre o assédio sexual, produzido pela Defensoria Pública do Estado de São Paulo em parceria com o Núcleo Especializado de Promoção e Defesa dos Direitos da Mulher e a ONG OLGA. Comecei mostrando o fôlder aos alunos e solicitei que falassem sobre o que estavam vendo. Os alunos não souberam nomear o gênero, entretanto, reconheciam a sua funcionalidade, porque disseram que era um texto que servia para divulgar informações importantes para as pessoas. E geralmente, os assuntos eram sobre meio ambiente, a água, vacinação, ou seja, assuntos para alertar a população. Mostrei os balões de falas presentes na parte central do fôlder e interroguei-os sobre as palavras que apareciam neles, os alunos responderam que se tratavam do barulho do assobio e que, provavelmente 
seriam de homens "mexendo" com mulheres na rua. Chamei atenção para a cor vermelha que compõe boa parte do fôlder, para o formato do texto, a organização das informações, entre outras informações. Em seguida, realizamos uma leitura compartilhada, chamando atenção para as informações apresentadas. Algumas informações despertaram a atenção dos alunos, a saber: a diferença entre assédio e paquera, a questão da roupa das mulheres, as consequências do assédio e a definição de ato obsceno. Finalizamos com comentários breves feitos por escrito e oralmente. A atividade prevista foi substituída, mudei a rota, porque meus alunos precisavam saber um pouco mais sobre o assédio sexual. A seguir o fôlder lido e comentado:
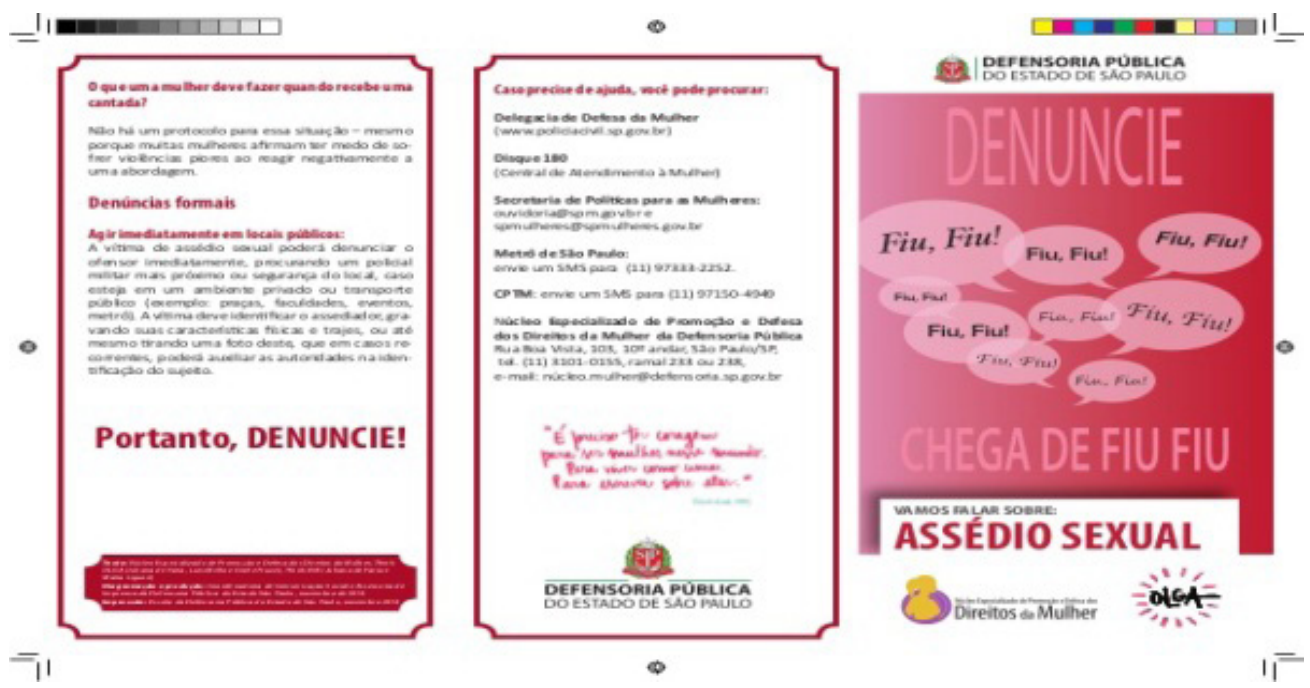

Conforme os dados, acima descritos, a ação pedagógica inicia com uma roda de conversa, portanto, com um gênero oral. A docente realiza esta ação estabelecendo um diálogo efetivo com os alunos, esclarecendo questões necessárias ao entendimento da atividade que está desenvolvendo. Fala do tema a ser abordado na aula e de sua relevância para a vida em sociedade, focando especificamente no assédio de que são vítimas as mulheres. Como podemos observar, a atitude de ensinar da professora e sua ação pedagógica corrobora uma intervenção consorciada com as práticas sociais em que estão imersos os aprendizes, fazendo-os enxergar a realidade de maneira crítica e reflexiva. Para isso, utiliza-se de gêneros como o fôlder, a partir do qual dialoga, posteriormente com outros gêneros. Focando também em outros aspectos constitutivos do gênero em questão, no caso, aspectos semióticos como cor, formato, organização das informações, o que reafirma a característica multimodal dos diferentes gêneros de texto.

Constata-se também que, nesse primeiro momento, a professora tem uma postura de estímulo/instigação em relação ao posicionamento oral dos alunos acerca do tema em discussão, assim como em relação a breves comentários escritos, de forma a despertar, nesses alunos, uma atitude reflexiva, que se centra numa interrelação necessária entre 
escrita, leitura, oralidade e reflexão linguística, que embora ainda aconteça de maneira incipiente, já configura uma relação dialógica entre essas atividades.

Ainda no âmbito da descrição e realização da ação pedagógica, na perspectiva das ADIs, Coelho relata o segundo momento dessa ação. Observemos o seu relato:

\section{$2^{\circ}$ Momento: Mais discussão! E pesquisa!}

Nessas aulas, demos continuidade às atividades do dia anterior. Retomei o assunto, realizando uma chuva de ideias a partir da palavra assédio sexual. Os alunos estavam bem motivados a participar, percebi por suas falas que houve compreensão sobre o assunto, pois a maioria dos alunos não se limitou a dizer uma palavra, mas traziam explicações interessantes, como por exemplo que assédio era invadir a privacidade de uma mulher sem o consentimento dela; que o estupro não era somente quando havia relação à força, mas também ao se tocar as partes íntimas de uma pessoa. Depois, dividi a turma em grupos, distribui um cartaz para cada um com enunciados diferentes, solicitei que realizassem a leitura, discutissem a partir do texto e por último, na roda, apresentassem oralmente o que pensavam sobre o tema em questão. As meninas, no momento da interação oral, relataram vários casos de violência, ocorridas no ônibus, em seus bairros, nos corredores da escola, na rua, entre outros lugares. Os meninos, por sua vez, defenderam-se dizendo que tinha menina que gostava da "sacanagem", inclusive algumas também passavam a mão neles. As argumentações deles revelaram um posicionamento machista por parte da grande maioria dos meninos. Esse comportamento dos rapazes gerou uma pequena discussão, porque as meninas não aceitaram, uma estudante, inclusive, questionou se quando eles andavam no "busão" alguma menina já tinha passado a mão neles. E se quando andavam apenas de bermuda alguma mulher queria passar a mão no peito deles. Sem uma resposta convincente, a aluna disse que as mulheres não podem se quer usar uma roupa mais decotada, porque são chamadas por nomes vulgares. Depois, passaram a discutir nos grupos sobre os cartazes que circularam no período de Carnaval e anotar questões e informações relevantes para socializarem posteriormente aos colegas em forma de seminário. Durante as exposições, muitos relatos de abuso foram trazidos pelas meninas. É importante ressaltar que o cartaz que mais gerou discussão foi o da figura 1, por causa da falta de liberdade que as mulheres têm em não poder usar determinados tipos de roupa. Os cartazes utilizados foram os seguintes: 


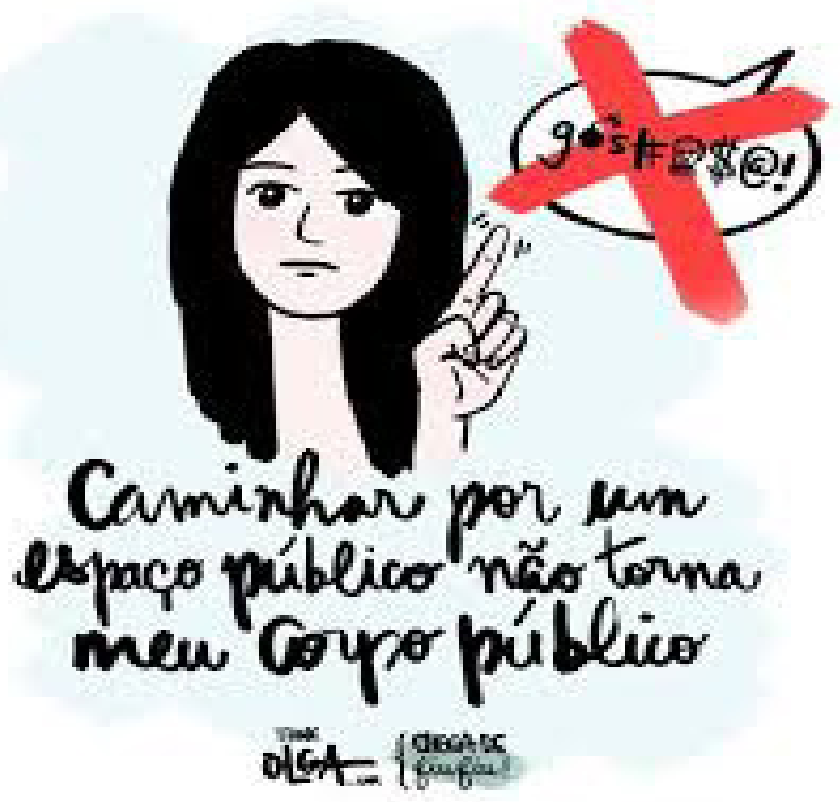

Figura 1. Campanha "chega de fiu fiu" Fonte: https://pin.it/hz5kzd7s32qhls

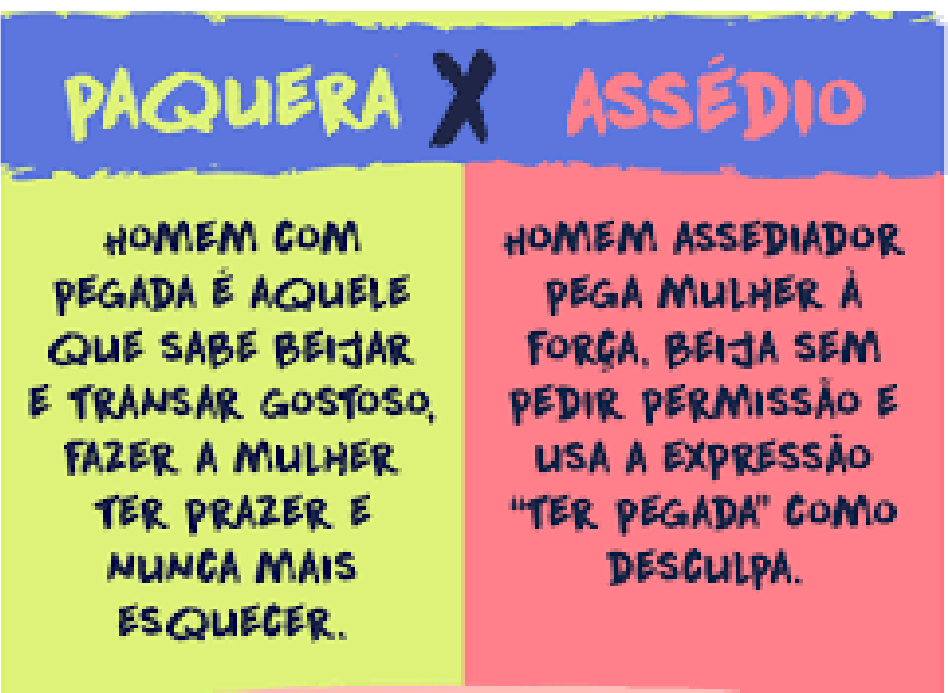

Figura 2. Guia prático e didático da diferença entre Paquera x Assédio Fonte: https://www.comunicaquemuda.com.br/paquera-x-assedio/ 


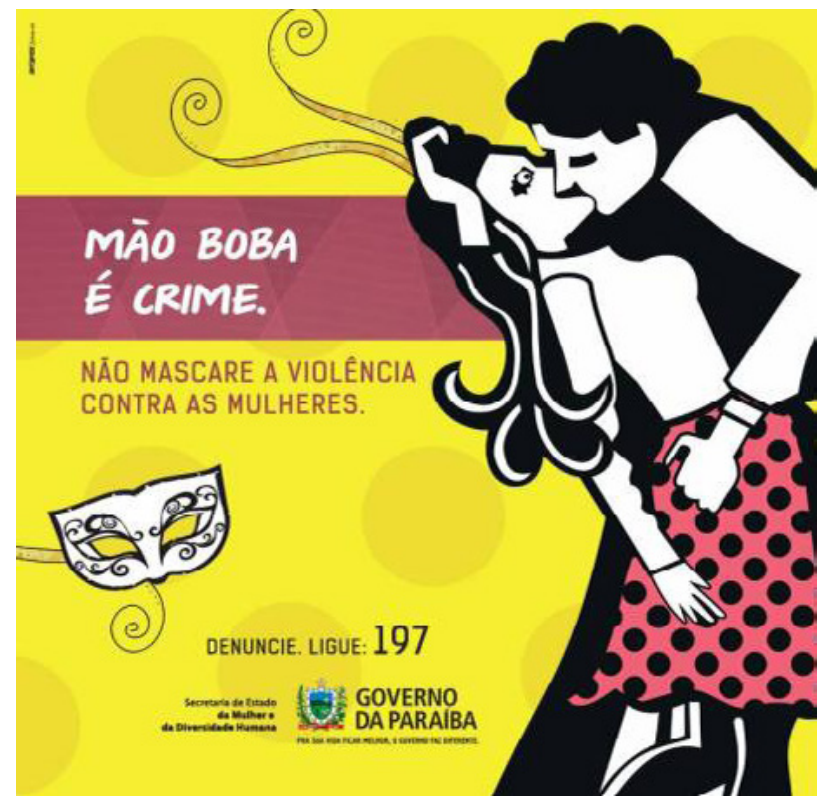

Figura 3. Mão boba é crime

Fonte: https://www.colunaviptocantins.com.br/destaques/item/20822-n\%C3\%A3osignifica-n\%C3\%A3o-e-o-carnaval-est\%C3\%A1-ai

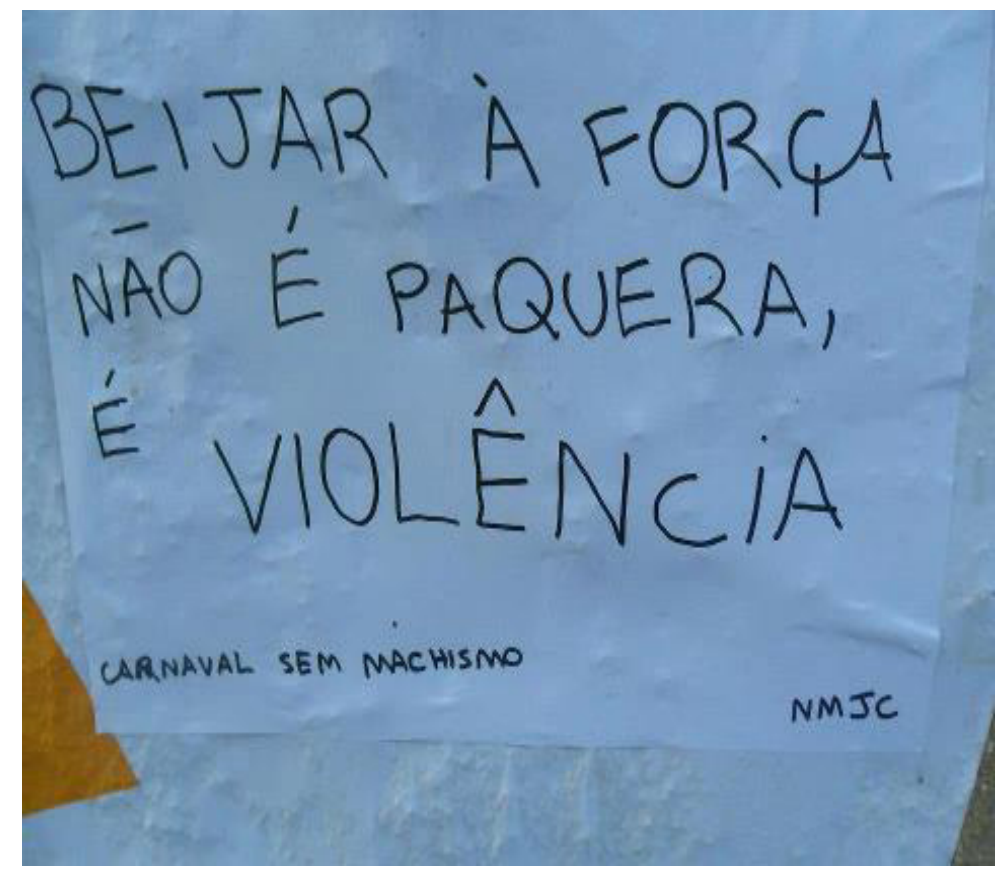

Figura 4. Carnaval sem machismo

Fonte: https://br.pinterest.com/pin/260434790923954454/?nic=1 
Ao término das discussões surgiu a ideia de produção de um panfleto. A sugestão foi dada, sobretudo pelas meninas que estavam bem motivadas com as novas informações descobertas. A intenção, segundo elas, era produzir um texto que circulasse, isto é, queriam sensibilizar as pessoas sobre a gravidade do problema, e sobretudo, encorajar as mulheres para que denunciassem os agressores. Foi a partir disso, ou seja, de fazer o texto circular que nós nos mobilizamos para articular com os agentes de trânsito do município de Santarém, porque a distribuição aconteceria em uma via pública bem movimentada próximo à escola. Mas era necessário mais informações, portanto, orientei-os a fazer uma pesquisa não apenas sobre o assédio, mas sobre os diversos tipos de violência contra as mulheres. Organizei o comando na lousa sobre os dados que precisariam pesquisar e fazer as devidas anotações de dados estatísticos, notícias, reportagens, entre outros. Dei como sugestão os sites seguintes:

Sites para a pesquisa:

- https://g1.globo.com/sao-paulo/noticia/mais-de-500-mulheres-sao-vitimasde-agressao-fisica-a-cada-hora-no-brasil-aponta-datafolha.ghtml.

- $\quad$ https://exame.abril.com.br/brasil/os-numeros-da-violencia-contra-mulheresno-brasil/.

- http://www.compromissoeatitude.org.br/tag/ibge/.

Fizeram a pesquisa, anotaram informações e também conversamos sobre os dados que descobriram. As meninas mostraram-se mais empenhadas na busca, inclusive fizeram questão de ler em voz alta vários dados sobre as mortes de mulheres negras. (COELHO, 2018, p. 39-41).

Nesse momento da ação pedagógica, a professora desenvolve atividades nas quais os alunos são levados a discutir oralmente o problema do assédio de que são vítimas as mulheres, observando-se, em tais discussões, posicionamentos antagônicos com relação ao tema. Para estimular o debate, a docente faz questões relevantes e instigadoras, distribui cartazes sobre a temática, o que leva as meninas a relatarem vários casos de violência ocorridos nos ônibus, em seus bairros, nos corredores da escola, na rua, o que provoca uma relação de defesa por parte dos meninos, em que dão voz a um discurso machista. Desse modo, as atividades de oralidade constituem um espaço necessário para inserção dos alunos não só no que está proposto pela professora em sala de aula, mas conduzem a uma reflexão crítico-cidadã acerca das práticas de linguagem, em seus diferentes gêneros e suportes, em circulação na sociedade contemporânea. Segundo o relato da professora, os alunos discutem nos grupos cartazes que circularam durante o 
Carnaval, socializando, no gênero seminário, os sentidos veiculados por esses cartazes, trazendo à tona relatos de abuso observados ou sofridos pelas meninas. Vale ressaltar que o seminário constitui um gênero importante para as discussões realizadas no âmbito do oral e o cartaz um instrumento discursivo crucial para a construção de uma prática cidadã que valoriza e respeita a diversidade de gênero/sexual de que se constitui a sociedade em seus diferentes segmentos.

Conforme o relato da professora, observamos que as atividades de leitura e oralidade não ficam centradas em si mesmas, mas provocam uma reflexão linguístico-discursiva e retórica sobre as práticas de linguagem em mobilização nas diferentes instâncias e espaços da sociedade, levando-se em conta, nesses contextos, posicionamentos machistas, autoritários, discriminatórios e excludentes, que precisam ser rompidos e superados. Cumpre esclarecer, segundo os relatos da professora, que as atividades, anteriormente mencionadas, levam os alunos à produção de um panfleto, cuja intenção, de acordo com as alunas, é fazer circular informações, de modo a sensibilizar as pessoas sobre a gravidade do problema e encorajar as mulheres a denunciar seus agressores.

Como visto, a ação pedagógica da professora leva à leitura/produção de vários gêneros textuais/discursivos, como dados estatísticos, notícias, reportagens, dentre outros, os quais devem fomentar a inserção dos aprendizes em atividades de leitura, que, por sua vez, conduzem às atividades orais, a uma reflexão sobre estas e, consequentemente, às práticas escritas que também se constituem como diversas, diferenciadas e até mesmo antagônicas. O trânsito necessário entre as atividades de leitura, oralidade, escrita e reflexão linguística (não necessariamente nesta ordem) constitui um instrumento essencial para a ampliação de uma capacidade discursivo-cidadã, política e sociorretórica, com a qual os indivíduos passam a tornar-se sujeitos de seus dizeres, refletindo metadiscursivamente sobre o que enunciam, de onde emanam tais enunciações, considerando, sobretudo, as consequências de seus dizeres para os contextos em que estão inseridos, levando-se também em conta, nesse âmbito, as transformações requeridas pela sociedade, que se quer democrática.

Observemos, agora, o terceiro momento da proposta didática da professora, em que considera relevante o diálogo com outros gêneros, como o ofício. Nesse momento dá destaque a interlocução dos cidadãos com as esferas de poder. Assim, o ofício e os gêneros institucionais similares constituem práticas sociais necessárias à implementação de políticas públicas, mormente aquelas voltadas para a valorização e respeito a determinados grupos e segmentos sociais. Vejamos o dado de Coelho (2018, p. 43-44): 


\title{
$3^{\circ}$ Momento: Conhecendo o gênero ofício: o que é? Para que serve? Onde circula?
}

\begin{abstract}
A partir da necessidade da comunicação entre a escola e a Secretaria Municipal de Trânsito de Santarém, para a colaboração desse órgão no ato da panfletagem, discutimos, durante um bate-papo, sobre um outro gênero, o ofício. Primeiramente, perguntei se sabiam o que era um ofício. Mas, para minha surpresa ninguém na turma conhecia esse gênero. Foi, então, que organizei os alunos em três grupos, distribui cópias de ofícios com assuntos diferentes para cada um deles, porém antes realizamos uma leitura compartilhada, porém, antes mesmo da minha intervenção, os alunos começaram a fazer perguntas sobre aquele texto, como por exemplo: O que é Of.? ILMO? O que representa a numeração no corpo do texto? O planejamento precisou ser redirecionado, porque para o desenvolvimento das atividades, havia um roteiro programado para a mediação sobre o gênero em foco. Mas, somente iniciamos pelas questões apresentadas pelos estudantes, depois retornamos para as questões a seguir:
\end{abstract}

Já leram um texto como esse? Como ele foi organizado no papel? Quem é o destinatário desse texto? Quem o escreveu e com qual propósito? Que símbolo é esse que aparece na parte central do texto? O que ele representa? Que número é esse que aparece no início do texto? O que significa a expressão ILMO? Por que esse termo é utilizado? Qual a finalidade do ofício? Quem o assinou?

A falta de contato com o gênero em análise não dificultou a compreensão. O que, em termos de linguagem, despertou a atenção dos alunos foi a variedade linguística utilizada, na verdade, foi a formalidade desse texto documental. Além disso, os assuntos apresentados no ofício desencadearam discussões que levaram a novos gêneros, inclusive, lemos alguns artigos da Constituição Federal, documento esse nunca antes visto pelos alunos. A atividade final foi apresentar as conclusões sobre o gênero ofício, resumidas em cartazes.

Para orientar os alunos na produção do gênero ofício, a professora coloca exemplos de textos de ofício, possibilitando aos alunos o contato com esse gênero e, ao mesmo tempo, mostrando a relevância social deste no que concerne à interlocução com as instâncias institucionais/governamentais. Desse modo, os modelos do gênero servem de parâmetro para a apropriação discursiva do que se requer de um ofício.

Veja-se, a seguir, um dos textos de ofício apresentados pela professora. Continuando sua atividade, a docente acompanha os alunos na produção de um ofício, cujo objetivo é solicitar a permissão para a atividade de panfletagem em determinadas áreas da universidade, tendo em conta a relevância do gênero panfleto no que se refere à construção de uma consciência reflexiva relativa aos direitos das mulheres, especificamente quanto 
ao respeito à sua identidade e às ações que estas desenvolvem na sociedade. Observe-se o ofício proposto por Coelho (2018, p. 45):

\section{Governo do Estado do Pará \\ Secretaria de Estado de Educação \\ Escola Estadual de Santarém}

Of. $n^{\circ} 054 / 2017 / D I R$

Santarém, 12 de dezembro de 2017.

IImo.(a). Sr.(a)

\section{Da: Direção da Escola Estadual Honorato Filgueiras}

\section{Para: Delegacia de Proteção à Criança e ao Adolescente}

Conforme solicitado, informamos os dados pessoais ${ }^{3}$ do aluno abaixo:

Aluno: João Silva de Sousa

Mãe: Joana Silva de Sousa

Pai: Francisco Rodrigues de Sousa

Endereço: Trav. Bolonha, 10051005, Bairro dos Cabanos.

Apresentamos nosso respeito e ficamos disponíveis para quaisquer esclarecimentos.

Atenciosamente,

Após a atividade de produção do ofício, a professora orienta quanto à construção/ elaboração do gênero panfleto, fornecendo informações necessárias à produção desse gênero, cujo objetivo sociocomunicativo é provocar uma reflexão acerca dos direitos das mulheres. Ainda no âmbito dessa atividade, a docente faz questionamentos sobre a estrutura comunicativa do gênero em estudo, exemplificando-o em um texto que versa sobre os direitos das mulheres no contexto de uma sociedade machista. Veja-se, a seguir, a descrição do $4^{\circ}$ momento, em que Coelho (2018, p. 48-50) descreve a atividade realizada, o que envolve a atividade de leitura/escritura:

3 Os dados, acima colocados, referentes a nome de aluno, mãe, pai e endereço são fictícios. 


\section{$4^{\circ}$ Momento: Que texto é esse?! 0 panfleto em foco...}

Nesse quarto momento, iniciei a aula promovendo a leitura de um panfleto (Figura 5) projetado no datashow. Antes de iniciar a leitura para fazer o levantamento dos conhecimentos prévios dos alunos, fiz os questionamentos a seguir: $\mathrm{O}$ que é um panfleto? Alguém já leu ou viu um panfleto? Onde? Dei um tempo para que os estudantes respondessem. A maioria afirmou já ter visto e recebido esse gênero textual, no centro comercial da cidade, mas geralmente não liam, porque, segundo eles eram só propaganda. Alguns alunos disseram que as pessoas que distribuíam panfletos eram "bem" remuneradas, pois recebiam trinta reais por dia. Em seguida, continuamos refletindo sobre o panfleto projetado na lousa, perguntei sobre para que servia aquele texto? Onde circulava? Quem o escrevia? Com que intenção escrevia? Qual era o tema abordado naquele panfleto? 0 que revelava o tema no texto? Em relação à parte não verbal, questionei: por que se utilizavam imagens? O que aparecia na imagem central? Que sentimentos a imagem despertava? O que aqueles olhos revelavam? Quais as cores predominavam? E por que utilizaram aquelas cores? E como o texto era organizado? E as letras? E os símbolos? Ficou evidente que apesar do panfleto ser um gênero com o qual a maioria tinha familiaridade, muitos desconheciam a funcionalidade de elementos textuais, gramaticais e, sobretudo, discursivos utilizados no panfleto. Segundo eles, nunca tinham atentado para a escolha das cores num determinado texto, achavam que serviam apenas para chamar a atenção, não sabiam que havia uma relação com as imagens e com a intenção do que o autor pretendia repassar aos seus interlocutores. Depois, aos estudantes organizados em grupos, foram distribuídas cópias de outros panfletos para que respondessem questões interpretativas sobre o texto e organizassem por escrito as suas descobertas sobre o gênero em estudo. 0 grupo pode escolher a maneira mais adequada para socializar as informações a partir da leitura realizada pelos seus componentes. 


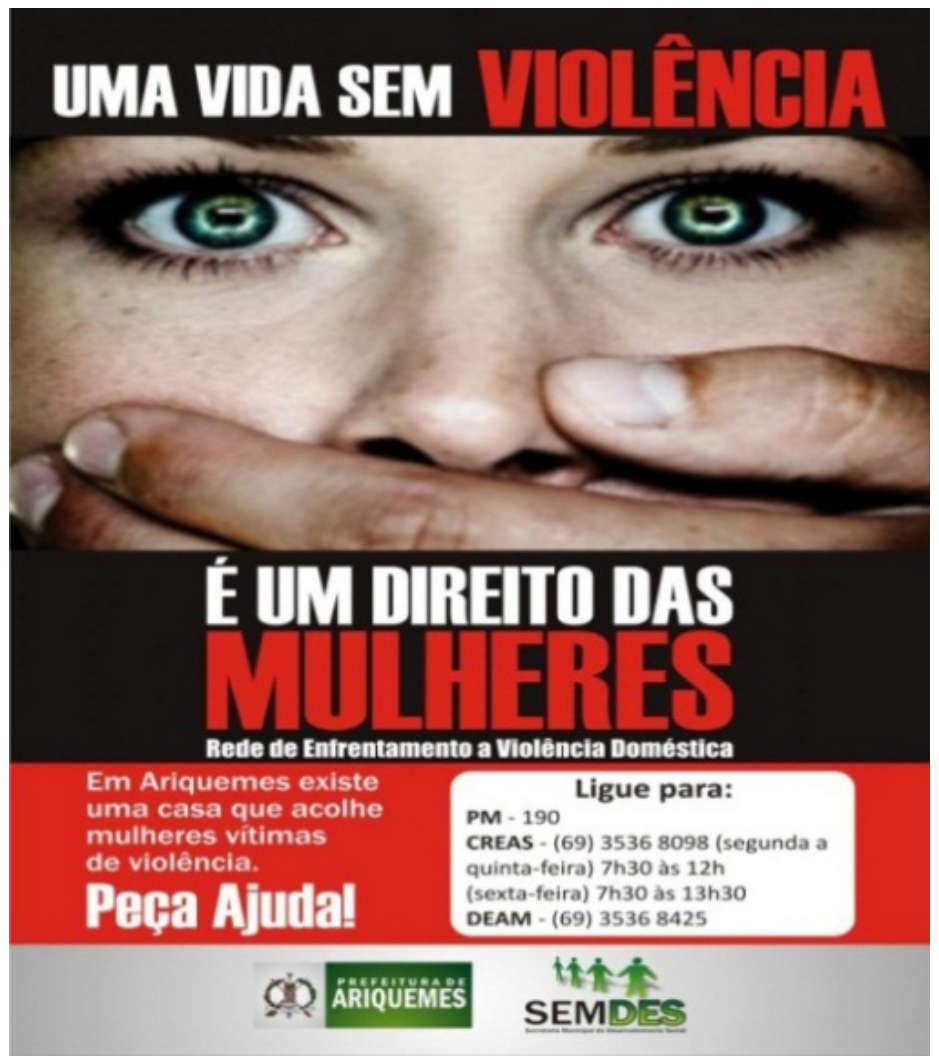

A atividade de leitura partiu dos questionamentos abaixo:

1. Que texto é esse? O que ele comunica?

2. A que público se dirige? Que elementos no texto indicam esse público a quem se destina?

3. Onde circula? Qual é o suporte?

4. Quem o escreve? Com qual propósito? Que marcas textuais revelam o propósito do autor?

5. Em relação à parte não verbal, observem cada parte do texto. O que sugere a imagem central? Quais são as cores predominantes? Por que a utilização dessas cores? Há símbolos? Números? Letras diferentes? Por quê?

6. Qual é o modo verbal presente no texto? Com qual finalidade foi utilizado?

7. Qual a variedade linguística utilizada no texto? Por que foi utilizada? 
Os alunos não apresentaram muitas dificuldades durante a análise, exceto nas questões relacionadas aos conhecimentos gramaticais, como por exemplo, o modo verbal, porque desconheciam a nomenclatura, mas compreendiam a funcionalidade dessa palavra no texto.

Conforme observado no discurso da professora, constata-se uma preocupação dela quanto à construção discursiva do gênero panfleto, na medida em que aponta para elementos dessa construção em termos de quatro itens constitutivos de qualquer gênero, a saber: tema, estrutura composicional, estilo e registro, como postulado em Bakhtin (2010a, 2016), considerando sempre a relação de reciprocidade entre os gêneros também no nível desses quatro elementos.

\section{Considerações finais}

As Atividades Didáticas Integradas de ensino de língua devem constituir um instrumento para a construção da cidadania, na medida em que os textos trabalhados em sala de aula levem a uma inserção mais efetiva dos sujeitos nas mais diversas práticas sociais. Assim, essas atividades devem estar consorciadas com essas práticas, já que os sujeitos, tendo em conta a sua condição enquanto indivíduos coletivos, precisam interferir nos vários espaços de produção de linguagem, nos quais as atividades de discursivização não são estanques, mas transitam umas pelas outras, exigindo dos cidadãos multiproficiências discursivas, especificamente quando refletem sobre o que falam, leem e escrevem, levando sempre em conta as especificidades dos espaços sociais por onde transitam.

\section{REFERÊNCIAS}

BAKHTIN, M. M. Notas sobre literatura, cultura e ciências humanas. São Paulo: Editora 34, 2017.

BAKHTIN, M. M. Os gêneros dos discursos. São Paulo: Editora 34, 2016.

BAKHTIN, M. M. Estética da criação verbal. São Paulo: WMF Martins Fontes, 2011.

BAKHTIN, M. M. Estética da criação verbal. São Paulo: WMF Martins Fontes, $2010 a$.

BAKHTIN, M. M. Para uma filosofia do ato responsável. São Carlos: Pedro \& João Editores, 2010b.

BAKHTIN, M. M. Marxismo e filosofia da linguagem. São Paulo: Hucitec, 2006. 
BAZERMAN, C. Gênero, agência e escrita. São Paulo: Cortez, 2011.

COELHO, R. M. da S. Projeto com atividades didáticas integradas (AD/s): uma proposta para o ensino de língua portuguesa. 2018. Dissertação (Mestrado Profissional em Letras) Universidade Federal do Oeste do Pará, Santarém, 2018.

HABERMAS, J. Teoria do agir comunicativo: racionalidade da ação e racionalização social. São Paulo: Editora WMF Martins Fontes, 2012.

KOCH, I. V. As tramas do texto. Rio de Janeiro: Nova Fronteira, 2008.

KOCH, I. V. Desvendando os segredos do texto. São Paulo: Cortez Editora, 2006.

KOCH, I. V. Introdução à linguística textual. São Paulo: Martins Fontes, 2004.

KOCH, I. V. A inter-ação pela linguagem. São Paulo: Contexto, 2003.

KOCH, I. V.; ELIAS V. M. Ler e compreender: os sentidos dos textos. São Paulo: Contexto, 2009a.

MARCUSCHI, L. A. Produção textual, análise de gêneros e compreensão. São Paulo: Parábola Editorial, 2008.

MARCUSCHI, L. A. Oralidade e ensino de língua: uma questão pouco "falada". In: DIONISIO, A. P.; BEZERRA, M. A. (org.). O livro didático de Português: múltiplos olhares. Rio de Janeiro: Lucerna, 2005.

MOURA, H. L. M. Atividades de produção escrita realizadas por alunos da educação básica: uma perspectiva interacionista e sociodiscursiva do ensino de língua materna. Mimeo, 2016.

MOURA, H. L. M. Atividades didáticas integradas no ensino de língua (AD/s): uma concepção dialógica e sociodiscursiva. Mimeo, 2017.

SCHNEUWLY, B.; DOLZ, J. Gêneros orais e escritos na escola. Campinas: Mercado de Letras, 2010. 